Student teachers' thinking about learning to teach: a study of student teachers of mathematics and science at the end of their initial training

Keith Postlethwaite (University of Exeter) and Linda Haggarty (The Open University)

Word count, excluding bibliography and abstract 9998

Total word count $\quad 11730$

Corresponding author: Prof Keith Postlethwaite, Graduate School of Education, University of Exeter, St Luke's Campus, Heavitree Rd., Exeter, EX1 2LU

k.c.postlethwaite@exeter.ac.uk 


\title{
Student teachers' thinking about learning to teach: a study of student teachers of mathematics and science at the end of their initial training
}

\begin{abstract}
Recent dominant models of student teacher learning include apprenticeship and reflective practice, but these are now being challenged, extended and enriched by broader socio-cultural models of learning. These new models direct attention to how learning is shaped by an interplay between the characteristics of the student teachers, their lecturers and their teacher mentors, and the characteristics of the university, schools and societal contexts within which these students, lecturers and mentors work. Socio-cultural theories also reveal the importance of how learning is transferred and transformed as the student teacher moves between different contexts (eg between university and school, or between one school and another).
\end{abstract}

In the context of teacher education in England, this paper explores the nature of student teachers' thinking at the end of their initial teacher education (ITE) programme, and questions how the student teachers learnt to think about teaching in these ways - in particular what they felt they learnt in the university and school contexts, and how they dealt with differences between the ideas which were valued in those different contexts.

Data were collected by questionnaire from a volunteer sample of student teachers of science and mathematics close to the end of their ITE course. Questions generally called for free response answers which were transcribed, coded and then related to a framework of ideas derived from our synthesis of socio-cultural theories of learning. From the insights gained we develop a theoretical understanding of the emerging aspects of student teachers' thinking and learning which we summarise under the term "progressive filtering". We discuss the relationship of this idea to the classical literature on socialization of teachers and on 'reality shock', and also relate this idea to Activity Theory. We illustrate how this theoretical framework offers insights that could enable ITE to address issues which have remained problematic for some time. 
Student teachers' thinking about learning to teach: a study of student teachers of mathematics and science at the end of their initial training

\section{1) Background}

In England during the 1980s, initial teacher education (ITE), increasingly became a major site for ideological struggle between the government and others, especially those in higher education, who had an interest in the professional formation of teachers (Furlong et al. 2000). What the government in England appeared to want was "a cadre of skilled technicians to deliver the school National Curriculum programmes of study in an effective and efficient way", (Richards, Harding, and Webb 1997 p6). Calderhead (2001 p780) argued that this in turn shaped their thinking about an appropriate curriculum for teachers, commenting that 'there has been a trend for government agencies to claim that it is well known which teaching approaches and strategies "work" and to make clear prescriptions for teachers' practice'. However, teacher educators in universities often saw teaching as responding to the complex needs of individual learners in a specific context, and therefore highlighted the need to educate student teachers to help them make multiple decisions in non-routine situations. Teaching was thus seen as an intellectually challenging task in which teachers continually examined and refined their practice, and as a task which emphasised the appropriateness of teaching decisions to the particular context in which they were being made (Darling-Hammond 2001).

There is little doubt that the government view has been very powerful in shaping ITE practices in England. As Furlong et al remarked:

"In the course of just 15 years, the system had been moved from one of diversity and autonomy to one of homogeneity and central control. What the government, and particularly the TTA ${ }^{1,}$ had wanted was a common system with common standards and procedures no matter who was providing the training or where; this was how the TTA defined quality. By the end of the 1990s this had been largely achieved." (Furlong et al. 2000 pp148-9)

\footnotetext{
${ }^{1}$ The TTA is the Teacher Training Agency. It has become The Training and Development Agency for Schools (TDA) and "...is the national agency and recognised sector body responsible for the training and development of the school workforce" (http://www.tda.gov.uk/about.aspx). Its remit covers England
} 
Compliance $^{2}$ with these TDA requirements is a 'high stakes' concern for ITE providers. In this context, it is by no means clear that there was much scope for the Darling-Hammond view of teaching to shape their practice.

Research in primary classrooms (Edwards and Protheroe 2003) has shown that, in this system, primary student teachers' attention seems to be directed towards polishing their own visible performance rather than at concern for learners. The authors further argue that when caught in an accountability-led system, teachers are encouraged to interpret teaching as efficient curriculum delivery rather than see it as 'risky attempts at interactively supporting pupil learning' (p239). We might conclude that primary student teachers are left with a ritual understanding, rather than a principled understanding, of teaching and learning (Edwards and Mercer 1987). However, it is not yet clear whether this is also the case for student teachers in secondary classrooms. What this paper sets out to report is research which seeks to develop an understanding of secondary student teacher learning within these contexts of policy and practice.

\section{2) Theoretical and conceptual framework informing the study}

In the 1980s, contrasting models of teacher learning included apprenticeship (Zeichner 1980; Beyer 1988), and reflective practice (Schön 1983; Zeichner and Liston 1987; Calderhead and Gates 1993). Of these, reflective practice became the dominant model in teacher education research and in the practice of many university Schools of Education (see, for example, Benton 1990). Reflective practice requires that a task of teaching be planned, enacted, evaluated and, as a result, reconceptualised: stages which are each informed by theoretical ideas, contextual demands, and values (Haggarty and Postlethwaite 2003). The reconceptualisation is the springboard for more effective planning and enacting of a subsequent task.

\footnotetext{
${ }^{2}$ Compliance is monitored by the Office for Standards in Education, Children's Services and Skills (OfSTED) which inspects and regulates care for children and young people, and inspects education and training for learners of all ages in England. Its non-executive Board, which is appointed by the Secretary of State for Children, Schools and Families, is responsible for the strategic direction of OfSTED (http://www.ofsted.gov.uk/Ofsted-home/About-us ). Inspections are a 'high stakes' activity as, in the context of teacher education, a poor inspection result can lead to a reduction in the number of trainees a provider can accept and, ultimately, in closure of a course.
} 
Despite its value in encouraging teachers to address questions about the "ends, means, and contexts of teaching" (Zeichner and Liston 1996, p77), reflective practice can be problematic for beginning teachers (Moore and Ash 2002). The reflective practice model is now being challenged, extended and enriched by arguments from Edwards et al (2002), by the sociological ideas of Bourdieu (Bourdieu 1977; Bourdieu and Passeron 1990), by aspects of Vygotskyan social constructivism (Richardson 1997), by Hodkinson and Hodkinson's (2005) idea of dispositions, by broader cultural models of learning (Hodkinson, Biesta, and James 2004; James and Biesta 2007) by further insights into the role of values (Pajares 1992; Poulson et al. 2001), and by Sfard and Prusak's (2005) idea of identity.

The work of Bourdieu provides a range of powerful conceptual tools: a "way of thinking and a manner of asking questions" (Mahar 1990: p3) that we argue can shed new light on teacher education. These tools include the notions of 'habitus' and 'field'.

Briefly, 'habitus' is "a durable but transposable set of dispositions, representing the physical and mental embodiment of the social but at the same time offering choices" (James and Bloomer 2001: p5),. 'Habitus' draws attention to the importance of individual histories and of social context on what an individual will see as possible in a learning situation: for example, what will count as good learning, what methods of learning will be embraced and what will be set aside (James and Biesta 2007). The reference to individual histories suggests that there will be individual differences in 'habitus'; the reference to social context opens up the possibility of 'collective habitus' within a professional group - what Atkinson and Delamont (1985, p316) refer to as the "profession's oral tradition and habitus". This is something to which we will return in the discussion. In relation to ITE, important aspects of a student teacher's 'habitus' would include how they were disposed to see the task of teaching, what personal, tacit theories they brought to that task, their expectations of what learning to teach would involve, how they were disposed to engage with the range of learning situations that they would encounter, what they felt was the motive of the teacher education enterprise, and what they expected to be the outcomes. A student teacher's 'habitus' will be affected by their gender, social class, and ethnicity, as well as their previous history as learners and 
their broader life history. We recognised that a university tutor's 'habitus', as well as that of a mentor in school, will have similar elements and similar influencing factors.

As James and Bloomer (1981) go on to explain, 'field' is "a structured system of social relations at micro and macro level, rather like a field of forces in which positions are defined relationally, that is, in relation to each other". In the 'field' of teacher education, key aspects will include the nature of the power relationships within the university (eg between student teacher and lecturer in a university seminar), and the different power relationships (eg between student teacher and mentor) within the school. Of great importance is the ways in which power is operationalised at micro and macro levels, eg through decisions about who is to make the summative judgments on students' progress, and through ways in which student teachers, university tutors, school mentors understand who should expect to take responsibility for initiating learning activities or ensuring that specific things that are meant to happen in the course (eg opportunities for observation) actually do happen. The notion of 'field' also goes wider to include: institutional expectations (sometimes developed into formal policies) - especially those relating to ITE and to more general teaching and assessment regimes in the university and school; the nature of resource allocation decisions at university and school; the histories of ITE activity in those institutions; the power relationships with external agencies such as the TDA; the resource and policy context of the teacher education system nationally.

The notion of 'habitus' identifies the student teacher as a key player in their own learning, bringing with them dispositions which will affect what and how they learn. This is entirely consistent with a social constructivist view of learning (Vygotsky 1978), which acknowledges the importance of the 'subjects' who are engaged in the learning, but social constructivism also adds three further factors to the picture. The first is 'more knowledgeable others' (especially university tutors and experienced teachers) who can scaffold learning in the student teacher's zone of proximal development. The second is the cognitive and physical 'tools' that the student teacher has available (or can strive to acquire) in order to facilitate the task of learning to teach. These might include cognitive tools such as an understanding of theories of learning, or of successful ways of managing pupil behaviour, procedural tools such as lesson plan templates, or 
physical tools such as a computer or interactive whiteboard. The third is the 'object' or motive of the enterprise - the (possibly different) things that the student teacher, the mentor and the university tutor are being driven by as they engage in the task of ITE. For example, the student's motive may be to learn to teach by trying a range of approaches; the mentor's may be to keep thing stable so that the class is easier to pick up when the student leaves. The notion of 'field' reminds us that student teachers' learning during ITE is embedded in a broad cultural context and cannot be understood without reference to the broader influences on the schools and university departments in which they learn and the bigger cultural picture into which those schools and universities fit.

The ideas discussed above provide a rich framework within which to think about student teacher learning in any context in which they are placed so as to learn to teach. However, a further complexity of teacher education is that most student teachers learn about teaching during their ITE programmes in at least three new contexts: the university and at least two school placements.

Developing an understanding of beginning teachers' learning both within and across these different contexts is essential (Peressini et al. 2004): each context determines what learning is possible and what is difficult, and influences what will count as 'good learning' (Greeno, Collins, and Resnick 1996). One implication is that moving from one context to another may well be problematic: some notions accepted in one context will be contested in another. However, this contestation can be the seed bed for new notions that could not be generated in either context alone, so the difficulties can be seen as opportunities for expanded learning, rather than as signs that one or other context is dealing in ideas that are irrelevant to the task in hand. We argue that it is essential to understand these processes of learning in different contexts and to investigate whether the potential for 'expansive transformation' (Fuller and Unwin 2004) is actually being realised.

Fuller and Unwin offer a further important perspective on student teacher learning in their research on workplace learning more generally. They develop the idea of workplaces as lying somewhere between restrictive and expansive learning environments. Their work suggests that a school which takes: 
....an expansive approach ... enriches and extends an individual's learning territory. It does this by providing access to new learning regions... which become part of and enlarge each person's overall learning territory. Extending the metaphor, the larger and more fertile the territory, the more opportunity the individual has for personal development and identity transformation. (Fuller and Unwin 2004 p141)

The idea of restricted and expansive learning environments is further developed in schools and classrooms by Hodkinson and Hodkinson (2005). They define an expansive environment as 'one that presents wideranging and diverse opportunities to learn, in a culture that values and supports learning' (p123). As Billett (2001) explains, this increases the affordances for learning at work and therefore the chances that individuals will want to learn from those affordances. In considering student teachers' experiences of learning to teach in school, the notion of how their school context approximates to an expansive learning environment could therefore be a useful analytical tool.

Billett (2004) also argues that learner participation in workplace practices is dually constituted between workplace affordances and how an individual chooses to engage with those affordances (p190). Thus we see the strong themes of affordance and identity intertwined to the extent that an individual's learning in a particular workplace context is unique. The workplace, and those with power in the workplace, (in our case the site for teaching practice and the mentor and subject department), can influence to a considerable extent the nature and quality of learning opportunities offered. What is learnt, however is only a part of this, since each individual will interpret what is offered within a personal context and history that has been shaped by their experiences in other groups, both prior and contemporary (Eraut 2004 p203).

Eraut's idea of a life history, or Bourdieu's notion of 'habitus', or Hodkinson and Hodkinson's idea of dispositions all begin to touch on the idea of identity. Sfard and Prusak (2005) prefer the term 'identity' because they argue that the term is seen as constantly created and re-created in interactions between people. Further, 'identities are man-made and collectively shaped rather than given' (p16). They define two types of identity: an actual identity consisting of narratives about the actual state of affairs, told in the present tense and formulated as factual assertions, and a designated identity consisting of narratives presenting what is expected to be the case. 


\begin{abstract}
One may expect to 'become a certain type of person' that is, to have some stories applicable to oneself...because they present the kind of future that she is designated to have according to others, in particular according to people in the position of authority and power. ... a person may be led to endorse certain narratives about herself without realizing that these are 'just stories' and that there are alternatives... a perceived persistent gap between actual and designated identities, especially if it involves critical elements, is likely to generate a sense of unhappiness. (Sfard and Prusak 2005 p18)
\end{abstract}

What is important here is the idea that a mentor (or head of department) in a position of power will have a designated identity for a student teacher, and it can be speculated that it is in the student's interests not only to accept this designated identity but also to work hard at closing the gap between their actual identity and that being designated. In other words, they are in danger of becoming, or at least trying to become, the kind of teacher that fits with the school's/mentor's/ department's notion of a good teacher.

It is clear that, from the socio-cultural perspective outlined above, we should expect a wide range of factors to influence how student teachers learn to teach. Our synthesis of this literature is that the factors which should be taken into account in seeking to understand teacher learning include:

The subject: the identity, actual and designated of the learner; their dispositions; personal expectations; previous history as a learner; broader life history

The context ${ }^{3}$ : power relationships in the university and school; institutional history in relation to ITE; institutional expectations and policies; the expectations of other people involved (eg pupils, parents, governors); resources; the external policy agenda; what learning is possible and what is difficult

The purpose: the motive of the enterprise; what learning is being sought; what will count as 'good learning'

Support for learning: the role of more knowledgeable others; their provision of scaffolding; the conceptual and physical tools available to the student (or that the student can strive to acquire)

Learning across contexts: restricted and expansive learning environments; contestation

\footnotetext{
${ }^{3}$ The use of the label 'context' for this set of factors is not meant to imply that they are merely the stage set within which teaching and learning to teach take place. The context is integral to those activities, shaping what is regarded as appropriate and what will be effective, and possibly being changed by those activities.
} 
This gives rise to two questions: first: "Can we understand student teachers' thinking about learning to teach in these terms?" and secondly, since the classroom learning of their pupils is affected by similar factors (James and Biesta 2007) "Can we understand the ways student teachers teach in these terms?" This second question was operationalised through a focus on the student teachers' accounts of factors that they felt influenced their decision making in the classroom. In the sense that it addresses how student teachers understand their own teaching, this is a question about one aspect of the products of their teacher education. The first question was operationalised through a focus on how student teachers think they are learning to teach, and how they expect to continue that learning in their first post. It is a question about the student teacher's understanding of processes of that teacher education.

To provide a culturally informed insight into both these products and processes of teacher education we therefore sought to answer two research questions:

- what did student teachers say about the factors that affected their decision-making about their own teaching at the end of their training programme?

- $\quad$ how did the student teachers think that they learnt to teach?

\section{3) Methodology}

Data for the paper were collected by hard copy questionnaire from a volunteer sample of student teachers of science and mathematics close to the end of their ITE course. Items for this instrument were developed through discussion with our teacher educator colleagues and piloted with a group of student teachers in the previous year's cohort. Ideally the questionnaire data would have been followed up by interview, but resources were not available to do this in the unfunded research reported here. Although this is a weakness of this paper in isolation, as part of a later funded project, we were able to carry out follow-up interviews and observations of these student teachers in their first year of teaching, and results of that work are reported elsewhere (eg Haggarty and Postlethwaite 2009). On the questionnaire, we asked student teachers to write about the products and processes of their learning in response to fairly broad prompt questions. We then used the theoretical framework developed above to make sense of what the student teachers said. We 
therefore explored what they saw as the important elements of their learning. We did not develop specific questions that explored what the different factors of our cultural framework meant to us in the context of teaching and learning to teach. Although this might have led to an easier task of analysis and reporting, we felt it would lead the respondents too strongly and simply generate insights into what student teachers thought about what we saw as the important issues.

Our focus was on the learning of student teachers of science and mathematics. This partly reflected our own professional histories as ITE lecturers in these two areas. It was also a reflection of our belief that understanding (and ultimately improving) student teacher learning in these subjects is important if the current $\mathrm{STEM}^{4}$ agenda is to be addressed in any meaningful way. Although the two subjects are superficially rather similar, their common pedagogical practices are quite different. The two subjects therefore also gave opportunities to explore similarities and differences in thinking across two different teaching and learning cultures.

The original intention was to explore the thinking of students who had followed different initial training routes - a 'standard' $\mathrm{PGCE}^{5}$, a flexible $\mathrm{PGCE}^{6}$ and a $\mathrm{GTP}^{7}$ route. In the event it proved very difficult to recruit enough students (especially GTP students) to do this, so no substantive findings can be reported about differences amongst these training routes. The results are therefore reported across the sample as a whole. Given this difficulty in recruiting GTP students, all but one of our respondents were following courses on which we had taught. This gave us the opportunity to link student teachers' answers to an understanding of the content and structure of their courses. It also raised a difficulty in that students might have felt inhibited in writing anything that they felt was critical of the course. Although this is a potential weakness of the research, the timing of the questionnaire towards the end of the programme may have

\footnotetext{
${ }^{4}$ The government identified STEM as a national priority in England, aimed at producing a workforce that is well educated in all aspects of science, technology, engineering and mathematics. See www.qca.org.uk/stem for further details

${ }^{5}$ Post-Graduate Certificate in Education - a one year teacher education programme for students holding a first degree which, for intending secondary school teachers, will be in a subject related to that which they are preparing to teach.

${ }^{6}$ A PGCE whose length, content and focus is responsive to the student's previous experience.

${ }^{7}$ A Graduate Teacher Programme - an employment-based programme that allows graduates to train while they are employed to teach in school
} 
mitigated the problem as there was little course contact between students and tutor-researchers after the questionnaires had been returned. In addition, all students were assured that we would work within the British Educational Research Association (BERA 2004) ethical guidelines and informed of the specific implications of this for the study. All respondents signed and returned a consent form.

Because we wanted detailed information about student teachers' views our questionnaire consisted mainly of free response questions. We felt that this was necessary to enable us to gain nuanced insights into student teachers' views. We were confident that the science and mathematics students would be comfortable with this format because of our experience of reviewing various written tasks that they completed as part of their ITE programmes. However, outside the formal requirement of a course, this approach may have limited the response rate as it was not possible for respondents to make a quick response to the questionnaire. In total, 27 responses were returned ( 8 mathematics and 19 science). This small sample cannot be considered representative of the courses involved: still less is it representative of the national population of mathematics and science students. Had we been seeking to test hypotheses about teacher education, this would have been a serious shortcoming. However our goal was to build a tentative theory, which (as indicated above) we were able to test in our own later work. With this goal in mind, a small sample of students willing to invest time in providing substantial comments about their experiences of learning to teach, whilst still a weakness of the research, was acceptable.

Students' free response answers to the questionnaire were transcribed and then examined in detail by both authors who independently read and grouped answers. We then debated our interpretations with one another until we came to full agreement about these groupings, and then agreed 'labels' for the groupings (eg student teacher confidence; pupil expectations). We then gathered groupings together under broader headings derived from the theoretical framework outlined above. Given the debate about qualitative data analysis software (Garcia-Horta and Guerra-Ramos 2009), and the relatively small amount of data in our project, we did this analysis without the support of specialist software, though we did use Excel to help us to examine the groups of data as we established them. For example we gave numerical codes to each statement and then used the 'autofilter' facility to examine all statements that we had grouped under one 
code. We were then able to review decisions about the groupings and to refine our decisions about the labels that we applied to them.

\section{4) Findings}

In each the sections below there were few instances of differences between the mathematics and science students. Therefore we mainly discuss the sample as a whole rather then the subject sub-divisions within it (though differences between science and mathematics students are noted when they occur)

\section{1) Student teachers' accounts of the factors that they thought had affected their decision making in their own teaching}

The questionnaire asked student teachers to address this issue, by asking "Based on your experience, what kinds of things affect the decisions you make in your classroom?’. Our data therefore provide insights into the things that the student teachers felt had influenced their decision making. These student perceptions matter if we wish to encourage the students to be open to other influences. However, the data do not relate to the actual decisions being made. It is also important to acknowledge that other methods of studying decision making might lead to different insights into the process. The student teachers' responses are summarised in Table 1 which shows the kinds of statement most often made in relation to each factor and the total number of statements related to that factor. Several statements referred to more than one factor and many made it clear that interactions between these aspects were important. 
Table 1 Factors that student teachers thought had affected their decision making in their classrooms

\begin{tabular}{|l|c|}
\hline Relevant factor - example of the kind of statement most often made & $\begin{array}{l}\text { Total no. of } \\
\text { responses }\end{array}$ \\
\hline Subject - eg the impact of their personal characteristics & 12 \\
\hline Context - eg physical resources, expectations of others & 65 \\
\hline Purpose - eg achieving planned learning outcomes & 14 \\
\hline Support for learning - eg tools they could use & 7 \\
\hline Learning across contexts - eg previous experience and school & 1 \\
\hline
\end{tabular}

This table suggests that the respondents, as a group (though not necessarily as individuals), recognised the relevance of the range of ideas identified in our synthesis of the literature to their decision making. The reflective practice frameworks that were basic to these students' teacher education courses could be expected to produce this outcome, and the evidence suggests that they did. However, in comparison with the richness of the ideas in the literature, the kinds of statements made by the student teachers were rather restricted.

To give a richer picture of what student teachers had learnt to take into account in their decision making, and to identify gaps in their thinking, we next report a more detailed summary of the statements they made.

4.1.1) The influence of the subject (ie the student teacher themselves)

Student teachers argued that their classroom decision-making was affected by

" Me - eg how do I feel, do I have a lesson next period ? etc";

"Preparation; My mood.";

"My confidence with the subject and my personal energy level at that time.".

The issue of confidence in subject knowledge about the topic being taught was mentioned in 3 statements, one of which elaborated the issue as follows:

"My handling of a subject is affected by my confidence in subject knowledge, this leads to how

“open” I make the lesson. Uncertainty on any aspect of the material closes down those avenues that 
would normally promote pupils to learn for themselves, rather than being guided down a tightly

focused path, that is safe for me."

It is interesting that there was no recognition of the influence of students' past experience, personal history or personal theories of teaching or learning. Student teachers therefore recognised the influence of some aspects of 'habitus' but certainly not all.

\subsection{2) The influence of context,}

This was the dominant category of response with 65 of the 99 responses referring to matters of context.as something which student teachers felt had influenced their decision-making. One important issue was the expectations of their teacher colleagues and of the school. For example, one student mentioned that decisions about their teaching were affected by "The support of my department and school generally for trying new ideas."

Others commented on the importance of the support available in class from adults other than teachers, (eg teaching assistants and technicians).

Student teachers mentioned that decisions were affected by the size of the class and the arrangement of the workspace. For example:

"Size of class: if a classroom is full and crowded it's difficult to change seating either for groups or to isolate disruptive pupils. In smaller classes I feel more able to scan the class, differentiate and work with different groups or individuals. In a large class I find it hard to get round to everyone."

They also referred to the impact of resources: one student teacher wrote that "Classroom set up, facilities and resources - can limit what is easily deliverable", and another commented on the "Availability of resources to teach (ICT/equipment/chemicals)".

However a particularly common comment was about the nature of the pupils. Student teachers mentioned:

- $\quad$ pupils’ ability, (eg “class ability, range of ability...”), apparently viewing this as a stable characteristic of the class; 
- pupil or class behaviour. For example:

“...Having to spend entire lessons cajoling, threatening, persuading and reminding, sometimes stops me from utilizing my full repertoire of learning experiences for the sake of the overall classroom aura."

- the personality and mood of the class (the first perhaps being a fairly stable characteristic, the second being variable from lesson to lesson). Some students noted that this mood could be affected by the time of day, week, or year and the weather:

"I have realized how the time of the lesson affects the ability of pupils to digest information and has a significant bearing on what activities can and should be used."

- the expectations of the class. For example:

"The expectations of the class have been a big influence, taking over from existing teachers for whom the pupils have a relationship for good or bad."

Another student explained that it was important to fit in with such expectations rather than challenge them because "I'm only "borrowing" groups for limited periods of time".

Students made further context comments that could be seen as relating to the policies, rules and targets of the school and to structures such as the school timetable. One student also mentioned that rules that were carried over from their PGCE experience would have a (probably unintended) effect:

"the PGCE "document everything" culture means that I still find it difficult to make major decisions to change things mid-lesson".

These comments reflect both physical aspects of context (eg resources) and social aspects (especially the expectations of colleagues). There was, however, little explicit recognition of power relationships, or of broader influences such as the expectations of parents or school management, or of the broader educational context within which the school operated. 


\subsection{3) The purpose of the teaching.}

Fourteen students made relevant statements about this, usually seeing "purpose" as something which influenced their decision-making about lesson objectives: the purpose of their leason affected decisionmaking in relation to choosing objectives at the planning stage, and decision-making in the course of the lesson itself about how, in the light of pupil responses, those objectives might be changed - or how the teaching might be changed to continue to address them. Eleven students specifically mentioned this need to change teaching in the light of pupil responses:

\footnotetext{
"I have also seen how general pupil behaviour leads to the need to make decisions such as cutting parts of a lesson or using a different method to meet the learning objectives than conventional approaches."

"Unexpected answers to questions can result in a change of focus or a brief diversion."

"The responsiveness of the pupils; tasks can sometimes take longer or shorter than planned."
}

Although one of these three students clearly mentioned the goal of meeting learning objectives, it is possible that the purpose of the teaching for others related to different aspects of 'teaching performance' (eg for the third student quoted above it was perhaps about 'getting through the material').

Given that some student teachers referred to decision-making about the purpose of their lesson at the stage of planning that lesson, it was interesting that only one referred explicitly to the National Curriculum, and none mentioned schemes of work, examination specifications or the key concepts within the subject, as factors that would affect their understanding of that purpose.

\subsection{4) Support for Learning}

In relation to the way in which their decisions were affected by the ways they could provide support for learning, student teachers (mainly scientists) made seven comments that could be considered to be about tools which they could use in their teaching. These students almost always referred to 'concrete tools' such as equipment or to ICT resources whose availability (or otherwise) affected the decisions they took. (In this respect, statements labeled 'support for learning' overlapped with those labeled 'context'.) 
Only one student teacher commented that theoretical ideas from the university served as useful tools to shape their decision making in class, noting moreover that

"The ideas presented in the PGCE course and readings tend to be easier to apply at the planning beforehand stage, rather than in the classroom".

One example of this lack of reference to theory in classroom decision making is that although student teachers considered some aspects of pupil characteristics in their decision making, no-one wrote about the importance of knowing about the previous learning of individual pupils which, from a constructivist or social constructivist theoretical viewpoint would certainly be expected to shape the support they provided. Another is that no-one discussed decision making affected by pedagogical content knowledge (Shulman 1987): eg the range of analogies, models, demonstrations, motivating facts, or useful text book/internet resources that they might choose between in order to support learning. This perhaps suggests that decision making focused less on pupil learning and more on other aspects of managing a classroom.

We conclude that further attention is needed to the question of how to bring the tool of theoretical ideas into the classroom discourse for student teachers so that it begins to influence decision-making (especially decision-making about learning) in a more explicit way. Given the comment on planning above, maybe further attention to its role in planning would be a good way to begin this process. Given the dominant role given to school mentors in the discussion below of how student teachers learn, it would seem critical to ensure that mentors are part of this process of drawing on theory in the dialogue about classroom decisionmaking.

\subsection{5) Learning across contexts}

In terms of learning across contexts there were no examples of student teachers highlighting ways in which their decision making was affected by consideration of the different contexts in which their pupils learn ideas (eg pupils learning graph drawing in mathematics then using it in science). There was also no reference to the influence on their decision making of aspects of their own thinking that had emerged from a struggle to reconcile contrasting ideas from school and university (despite the students from two of the courses under study being explicitly alerted to this issue). However one student teacher of mathematics 
commented that "coming from a low volume training environment, as well as having obtained a post-16 PGCE, my natural inclination is personal assistance but this is difficult in a large classroom environment and means the elements of inclusion and differentiation become hard to ensure". There is awareness here of a discontinuity between personal expectations and his current situation, though (in these comments at least) no indication of how this discontinuity might lead to new thinking and practice on his part.

\subsection{6) Summary of factors affecting student teachers' decision making}

The image of student teachers' decision making that is represented here emphasizes the influence of the people involved (the student teacher themselves, their pupils, the teachers and other adults with whom they work). It highlights the dynamic nature of their teaching, affected, as lessons unfold, by pupil behaviour, pupil reaction and pupil expectation, but also perhaps tied down by the (assumed and perhaps overstated) course expectation that everything will be documented. Since student teacher characteristics and some pupil characteristics affected their decision making about teaching so much, student teachers' concerns for "what works" is likely to be highly contextualized - ie to be re-framed as a concern for "what works for me, for these pupils". It follows that technicist prescriptions of 'best practice' applicable to all teaching situations were unlikely to be seen as definitive by these student teachers. However, it is also apparent that they had not yet constructed a professional understanding that might help them to be, in Richard's words that we quoted earlier: "imaginative, creative teachers whose informed professional judgement leads to intelligent action". In particular, there is little here that suggests the importance of ideas and theories in informing student teachers' decision making, little that suggests that they problematised the purpose of their lessons, and little to suggest that they were exercised by essentially moral decisions about what ought to be taught in relation to their subject or to a particular topic. Furthermore, since student teachers made no reference to the prior learning or to the misconceptions of their pupils, it would seem that the role of these factors in shaping learning is not being recognised as part of student teacher decision making.

We now turn to our second concern: how did these student teachers learn to teach? 


\section{2) Student teachers' thinking about their learning to teach}

We approached this in four ways: we asked what they did well and how they had learnt to do that; we asked what they wanted to improve and how they thought they would go about making that improvement; we asked them to consider who would help them in their induction year to learn more about teaching and how; we asked them to identify three key ideas that would improve teaching generally and how they had learnt those ideas. We analysed the responses to each of these questions in the ways reported in Section 4,1 but for reasons of space will not describe this analysis in detail. Instead we will comment on two major themes which we identified in the set of questions and which articulate with the ideas reported so far: first that student teachers mentioned different factors as influencing different aspects of their learning; secondly the issue of the relationship between different ideas - whether student teachers learnt from synergy or from contestation.

\subsection{1) Different aspects of learning, different factors}

The questions above gave us insights into four aspects of student teacher learning. In explaining how they had learnt to do the things that they thought they now did well, their personal characteristics as subjects were a significant factor: over half the group felt that their learning related to things they did well was influenced by characteristics they were "born with", or had been developed in a previous career. As one student, writing of their success in learning to manage the varied demands of teaching said: "I am positive, enthusiastic, organized and creative: I was born like this! My family is like this!”

No-one wrote about purpose as a factor affecting how they learnt to do the things that they did well, yet there are clearly ways in which matters of purpose can be relevant. For example, clarity about and empathy with the purpose of a course task might be expected to contribute to student teacher motivation in mastering it.

All the other socio-cultural factors discussed in Table 1 were represented in statements about learning to do things well, but the balance amongst the factors was very different. As shown in Table 1, context was a 
major influence on classroom decision making, but only one student recognised that sensitivity to context had helped him/her to learn to do something well. In contrast, support for learning and learning across contexts were much more evident when student teachers discussed their own learning than when they reflected on their decision making in their classroom.

When student teachers wrote about how they would learn to improve aspects of their teaching, the balance of influential factors was different again.

Although students attributed strong aspects of their teaching to their own characteristics as subject, no one considered that weaker areas in their teaching might have been influenced by some less appropriate aspect of their identity.

Four student teachers wrote about the need to explore the context of their school - especially its behaviour management systems and policies. These student teachers' responses suggested that improvement in their behaviour management would be achieved through awareness of, and conformity to, existing school systems, rather than, say, through an examination of underlying factors which might contribute to the problem. There were few comments which explicitly referred to broader aspects of context such as national curriculum and testing requirements.

The overwhelming majority of student teachers wrote about how to learn to improve their teaching in terms of using the support for learning that was available to them. They almost always referred to learning from experienced colleagues, though some also mentioned other sources of support such as talking to/observing teachers and teaching assistants; practising themselves; "acquiring resources"; reading books, websites and university materials.

Only one student teacher referred to issues relating to learning across contexts. This student was aware of the difficulties inherent in her forthcoming move to a new school: 
“...my second placement was an independent school and my job is in a comp so I need to brush up on (classroom management) strategies appropriate to that environment. I have also had to work hard on presence which seems to suffer when I change school."

It is interesting that even this report provided no evidence that they saw a significant place for university input or for theoretical ideas generally in the development of their practice.

Looking ahead to learning in their induction period, the dominant source of support for learning was, as might be expected, experienced colleagues in school. They expected their induction mentor to provide insight into school systems, to be reactive suggesting solutions when problems arose, to provide personal support, and to be proactive suggesting areas for professional development. For example one student felt that the mentor could offer support in relation to "Whole school life, pastoral system, personal happiness and job satisfaction."- a somewhat unrealistic expectation!

Students (mainly scientists) also saw the head of department as a key source of support; both scientists and mathematicians mentioned the role of 'other teachers'.

Only one reference was made to the possible impact of university ideas on this phase of teacher learning.

When student were asked to comment on how they had learnt ideas that would be useful in improving education generally, one suggestion was based on the subject characteristic of 'past experience'. Twenty were based on support for learning provided by colleagues in school. Thirteen were based on both university and school input. However, 24 statements were based on support from the university alone. It is interesting that this university input was separated from school experience in this aspect of student teacher thinking, and that university input featured more strongly in student teachers' thinking about general improvements in education than it did in ways in which they could improve their own teaching.

It is also interesting that some students did not refer to university influence in relation to a given topic even when, given our knowledge of the nature of their university courses, we were clear that university input had been provided. We suggest that when these ideas were offered in the university programme, such students 
were not able to learn from them or value them (Haggarty 1995). They were perhaps only learnt or valued when they reappeared in the school context, and they were then (sometimes) perceived as having been first introduced in that context.

The picture that we see from these results and those in Section 4.1, is of theory informing general thinking about education, providing an influence on things that the student teacher was doing successfully, being of some use in their planning, but being disregarded as a source of improvement in teaching (either during initial training or in induction) and as a basis for decision making in the classroom. Perhaps there is a tendency to see classroom practice as an untheorised activity: for decision making to be based on context, and personal learning to be a matter of taking ideas and support from experienced colleagues. We will return to this issue in our overall discussion.

\subsection{2) Synergy and Contestation}

Student teachers wrote about the importance of situations where different factors influenced their thinking or practice in the same direction - where there was synergy between different influences on teaching. Such issues emerged most strongly when student teachers were discussing how they developed the skills that they felt they did well.

This is illustrated by comments that show the importance of synergy between subject characteristics and school context. Some related to students' skills in lesson planning:

"Planning: (I've) always been quite organized, but (have been) shown by my PST that planning is the key: if you know what you're doing, and you've planned a fun and interactive lesson, with some back up ideas, then you feel more confident."

Some related to time management:

"I am disciplined in the use of time: The help from staff at my placement schools and my organizational skills combined to make this one of my strengths."

Others concerned strengths at establishing and developing positive relationships with pupil. 
Students often noted that things they did well were things where the skills they brought with them were endorsed by what they encountered in school or in the university:

"This is a skill I brought into teaching but it has been extended and developed by observation of experienced teachers in classrooms and form rooms."

There were no examples of contestation: of strengths developing through a challenge to identity presented by the school or university situation.

Another set of comments related to learning across contexts. Five comments explicitly described situations where strengths were developed through synergy between ideas from school and university:

"The (course) modules help me develop a structure for lesson planning that was then enhanced by my mentor in my first school placement"

"Use plenaries to assess learning: At uni during the first term of my PGCE I was introduced to the idea of AFL [Assessment for Learning] . The idea of introducing the aim of a lesson to students only seemed relevant if you were going to assess the success of this aim at the end of the lesson, specifically, and used some of the plenary and starter ideas suggested by various teachers tailored to the learning objectives in each class."

The synergy was working in different ways in these two cases. In the first case there was a common thread in university and school support; in the second each context provided a different part of a common story: a principle was introduced at university and school experience provided examples of related specific techniques.

No statement described learning emerging from a juxtaposition of differing ideas from two or more contexts.

\section{5) Discussion}

Two issues seem to us to be especially important in the findings reported above. First, the socio-cultural view of learning to teach which we outlined above was valuable: it defines concepts that helped in the construction of our understanding of student teachers' experience: it gives a structure to the range of things that student teachers said; it highlights things that were not being said. Secondly we argue that the 
students' dominant concern can be understood as the achievement of synergy - of conformity with the expectations and practices of their school. One consequence of this concern with synergy was that aspects of students' characteristics as 'subject' that were reflected in what their schools expected were seen as powerful; there was no evidence of engagement with aspects which were not reflected in school expectations - no discussion of how the student teacher might re-cast their personal story to move further in their own professional development; no discussion of how contrasting characteristics might be viewed positively to develop school practice. A further consequence was that although aspects of university learning that matched school expectations and practices were valued, there was no discussion of how ideas that contest these practices were examined critically in the school context or were used as stimuli for innovative practice on the part of the student teacher or any colleague.

Given that the questionnaire format enabled respondents to write at some length and with some sophistication about such matters as synergy between different influences on their learning, it is interesting that there was no mention of contradictory influences. Opportunities for expansive learning across contexts seem not to have been exploited; opportunities to contest the validity of dispositions based on personal histories seem to have been ignored. A key feature of the courses that the respondents attended was that they promoted an explicit reflective approach to teacher education in which student teachers were encouraged to expect such contrasts, to look seriously at theory and at their particular school context and to consider how theoretical ideas or personal dispositions which challenged current practice might be used to produce new context-specific thinking and action. This was done in one course, for example, through engaging students with explicit models of teacher learning, and requiring them to discuss with one another examples of creative tension between theories and practices in school. Yet even in these carefully engineered circumstances, creative tension between theory and practice did not feature as an element in student teacher learning.

We argue that one possible way of understanding these findings this is through a notion of "progressive filtering" 
- Ideas presented in the University (or in other non-school resources such as reading or discussion in friendship groups) may be filtered by aspects of the student's actual identity so that only those which match that identity are attended to. Some of the ideas which pass through the filter may contribute to the development of areas of strength in the student teacher's teaching.

- The school is then the 'test for truth' that the student applies to ideas which 'survive' the identity filter. Ideas that survive this 'test' are often regarded as having been learnt in school even if they were first raised elsewhere

- Things that are not represented in the practice or discourse of the school are regarded as invalid at least in relation to the development of the student's teaching and in decision making in the classroom in that school. There is no indication that they are used to challenge practice.

- So there are two significant filters on students' learning - their history and their school experience

- The notion of designated identity (Sfard and Prusak 2005) and/or that of the development of collective habitus (Atkinson and Delamont 1985) may result in feedback loops through which the school alters the student's identity.

If the filter were to be applied again as the student moves from their first school placement to a second, (or from their teacher education course to a first post in teaching) there could be further reduction in the range of functional ideas available to the student teacher - only those represented in the student's actual identity, in the discourse of their first school and in the discourse of their second school being available for use in the classroom. Of course, no such filter would be absolute, but even if it were somewhat permeable to ideas that did not fit, the filter could have a limiting effect on the development of new teachers, as one consequence of such a filter would be that there would be no opportunity for working with ideas from one context that are contested in another. The promise that powerful learning might be achieved because knowledge grows more complex, and becomes more 'useful', through a learner's participation in different contexts (Borko and Putnam 1996) may therefore not be fulfilled.

The achievement of synergy with their school through this process of (progressive) filtering can be seen through several lenses. It could be seen as an entirely proper consequence of the context-sensitive decision 
making that is encouraged by reflective practice (Haggarty and Postlethwaite 2003). It could be seen as consistent with the 'principles of procedure' for effective educational practice that are set out by James and Biesta (2007).who argue that, in navigating the complexities of any learning situation, it is sensible to make decisions which exploit aspects where a number of influences point in the same direction. An essential element in these views of teacher decision-making is, however, that ideas that are not in synergy with a particular context should not be dismissed as invalid, but kept in abeyance for use when the situation changes, or when it becomes necessary to challenge existing orthodoxies. This was not a feature of student teacher responses in our study.

The emphasis on synergy also resonates with the work of Lave and Wenger (1991) on participation in a community of practice, and of Lacey (1977) on the socialization of beginning teachers. It is perhaps a sign of the power of this socialization process that its impact is still so dominant 30 years after Lacey's research, despite many changes to teacher education in the intervening years which have been designed to bring a wider range of influences to bear on a student teacher's thinking and practice. Its persistence might be explained as the student teacher's response to the 'reality shock' (Whiteside, Bernbaum, and Noble 1969) that they face on entry to school - their realisation that their school placement challenges their identity, their 'habitus', their as-yet-untested thinking about pedagogy, and even their values related to teaching. In the face on such an assault, their personal alignment with the institution they are joining and with colleagues who hold power in relation to the assessment of their training, is perhaps an entirely understandable response. This driver for the student may be matched by the benefits that the school gains when a new practitioner fills an existing niche, conforms to existing policy and does not 'rock the boat'. These benefits of socialization - of 'fitting in' - make it understandable as an influential process in teacher learning but do also suggest that if it is the only process in use, it may limit development, both personal and institutional.

In such a situation, it might be wise to encourage student teachers (and newly qualified teachers embarking on their induction year) to recognise that socialization will be a process in which they will engage, to accept that it has the benefits and limitations outlined above, but also to recognise that their professional 
development could be enhanced if they were to return, once settled and accepted in school, to ideas and ways of being that had to be set aside to enable this socialization to take place. Such an approach would need support from mentors who had a sophisticated understanding of beginning teacher learning so that they could take student teachers through and beyond the process of socialization. Such mentoring would engage constructively with both helpful and less helpful aspects of the student teacher's identity, and pay attention to all aspects of the student teacher's understanding of teaching and learning even when some of these conflict with the school's current practice. It would certainly involve challenge to the student teacher's ideas in light of the school's policies and practices, but must also encourage critical engagement with those policies and practices in light of the student teacher's thinking. This could be problematic. In what they describe as a systematic and narrative review of 170, largely empricial studies of beginner teacher mentoring, Hobson et al (2009 p211) argue that mentoring devotes

"little or insufficient attention to pedagogical issues, to the promotion of reflective practice incorporating an examination of principles behind the practice". (p211)"

They go on to say (p214) that mentor training is "extremely variable in nature and quality ... often focusing more on administrative aspects of the role than on developing mentors' ability to support and facilitate mentees' professional learning”.

If ITE programmes are to help student teachers to move beyond socialization, further development of approaches to mentoring would therefore seem to be called for along the lines outlined above. However, given the obvious power of the socialization process, we were concerned that simply to suggest further development of mentoring approaches may not be enough to bring about change. Therefore, in an attempt to gain further insight into these issues we turned to activity theory (Engeström 1995; Cole 1996; Engeström 2001; Engeström, Miettinen, and Punamäki 1999; Kaptelinin and Nardi 2006).

There is some consistency between the socio-cultural theoretical framework presented so far, and that of activity theory. The social constructivist notions of 'subject' 'object' and of 'tools' are elements of both; some aspects of 'field' have things in common with the activity theory ideas of 'community' and 'rules'; ideas of power relate to the activity theory idea of 'division of labour'. In addition, learning across contexts 
has some similarity to Engeström's idea of boundary crossing. However, these useful (though somewhat superficial) similarities mask some significant differences between the theoretical stances, and it is these that help to take the argument forward. In the space available, we will concentrate on just two issues.

Leontiev (1978) makes clear that as people engage in activities, there is scope for their characteristics to affect these activities and for these activities to reinforce, reorganize, extend and challenge their characteristics. Where student teachers recognise the importance of pre-existing characteristics (such as organizational ability) to the things they do well, perhaps this is a reflection of a comfortable situation where new activities required of them as part of learning to teach reinforce existing characteristics. Where teaching is seen to call for reorganization, extension or revision of a student's existing characteristics, the situation is less comfortable and students may not engage fully with activities designed to bring about such change. Maybe this is a mechanism for the filtering mentioned above.

However, activity theory is optimistic that new characteristics can be created, or existing ones revised, through activity. Certainly students may not be able to respond if they are simply told to 'get organised', but if activities are designed to promote the development of this characteristic, change could be expected. To continue with the example of a disposition towards being organised, there is no sense that a disorganized student is a lost cause. We may however be more successful in creating new dispositions towards organisation (a new 'story' of self as organized) if we acknowledge the kind of change that is being required - if, for example, we allow some discussion of why dispositions towards being organized have not been created through the previous activities in which the student has engaged in the past, and why such a disposition is important in the activity of teaching, and if we then create a shared motive for activities that support the development of a disposition towards a more organized approach. This is one example of the kind of sophisticated mentoring that we argued for above.

As Kaptelinin \& Nardi (2006) state, activity is about the development of subject and object, so there is no doubt that the activity theory expressed by Leontiev can be used to construct an understanding of the 
learning of "subjects" who are individual student teachers. However, the version of activity theory that is offered by Engeström takes a different view. As Edwards (2005) points out, this

“...aims at changing systems through provoking a collective reinterpretation of the object. As a result of these reinterpretations a system is reconfigured as participants reposition themselves in relation to the object and to each other".

The emphasis here is on changing the system not simply provoking change in the student teacher. Maybe when the only focus of change is the student, the emphasis is inevitably on fitting in with the system, filtering out other ideas which might challenge that system. Maybe to enable expansive learning to take place, the object of the activity should be about improving teaching and learning in the school (with the student teacher's classroom as one facet of that improvement). Such a focus would imply a commitment on the part of the system to explore change - to become a centre for enquiry about teaching and learning, and to do this is ways that are inclusive of student teachers. We are not suggesting that the student teacher should be left to promote such a stance in the system. We are suggesting that the system should exemplify a commitment to change through its own activity and that student teachers should be invited into that change activity. Their own learning would be enriched by involvement in that activity and they will have things to contribute to that activity. In particular, where school practice is problematised by its own enquiry, there will be an appropriate place for student teachers to raise ideas that are not in line with current practice, We have experience of the power of action research as a means of supporting such a stance within a school (Haggarty and Postlethwaite 2003), and evidence within that work of the way in which an NQT was empowered to develop his teaching through involvement in activity that was designed to change practice more widely in the school.

Finally we were struck by just how enthusiastic many of the students were about teaching:

"I knew little about the cycle of planning, monitoring, assessment (all the 'behind the scenes' stuff). Doing the course has given me a huge respect for the profession and the individuals that practice it. Thus, it has also given me a sense of pride in what I do, especially given the many challenges. I find the education literature (e.g. journal literature) fascinating and I have started to link theoretical ideas into what happens in my classroom." 
Such student teachers have a lot to offer as well as a lot to learn. Their involvement a school which is explicitly an enquiring community could take their practice, and that of their school, forward in significant ways. 


\section{References}

Atkinson, P, and S Delamont. 1985. Socialisation into Teaching: the research which lost its way. British Journal of Sociology of Education 6 (3):307-322.

Benton, P, ed. 1990. The Oxford Internship Scheme: Integration + Partnership in Initial Teacher Education. . London: Calouste Gulbenkian Foundation.

BERA. 2004. Revised Ethical Guidelines for Educational Research. Southwell: BERA.

Beyer, L. 1988. Knowing and acting: inquiry, ideology and educational studies. London: Falmer Press.

Billett, S. 2001. Learning through work: workplace affordances and individual engagement. Journal of Workplace Learning 13 (5):209-214.

2004. Learning through work. Workplace participatory practices. In Workplace Learning in Context, edited by H. Rainbird, A. Fuller and A. Munro. London: Routledge.

Borko, H., and R. Putnam. 1996. Learning to teach. In Handbook of Educational Psychology, edited by D. Berliner and R. Calfee. New York: Macmillan.

Bourdieu, P. 1977. Outline of a theory of practice. Cambridge: Cambridge University Press.

Bourdieu, P., and J-C. Passeron. 1990. Reproduction in education, society and culture. Translated by N. R. London: Sage.

Calderhead, J 2001. International Experiences of Teaching Reform. In Handbook of Research on Teaching. Fourth Edition, edited by V. Richardson: American Educational Research Association.

Calderhead, J. , and P. Gates, eds. 1993. Conceptualizing reflection in teacher development. London: Falmer Press.

Cole, M. 1996. Cultural Psychology: A once and future discipline. Cambridge,MA.: Belknap Press of Harvard University Press.

Darling-Hammond, L. 2001. Standards Setting in Teaching: Changes in Licensing, Certification and Assessment. In Handbook of Research on Teaching. Fourth Edition, edited by V. Richardson: American Educational Research Association.

Edwards, A. 'Cultural Historical Activity Theory and Learning: a relational turn', TLRP Annual Conference Keynote Address, University of Warwick, November 2005. 2005 [cited August 2009. Available from http://209.85.229.132/search?q=cache:4mN1QD2hV70J:www.education2.bham.ac.uk/documents/ research/liw/Edwards_TLRP \%252005.doc+systemic+change+activity+theory\&cd=7\&hl=en\&ct $=\mathrm{clnk} \& \mathrm{gl}=\mathrm{uk}$.

Edwards, A, and L Protheroe. 2003. Learning to See in Classrooms: what are student teachers learning about teaching and learning to teach in schools? British Educational Research Journal 29 (2):227242.

Edwards, A., P. Gilroy, and D. Hartley. 2002. Rethinking teacher education: collaborative responses to uncertainty. London: Routlege Falmer. 
Edwards, D , and N Mercer. 1987. Common Knowledge: the development of understanding in the classroom. London: Routledge.

Engeström, Y. 2001. Expansive learning at work: toward an activity theoretical reconceptualization. Journal of Education and Work 14 (1):133-156.

Engeström, Y, R. Miettinen, and R Punamäki. 1999. Perspectives on activity theory. Cambridge: Cambridge University Press.

Engeström, Y. 1995. Objects, contradictions and collaboration in medical cognition: an activity-theoretical perspective. Artificial Intelligence in Medicine 7:395-412.

Eraut, M. 2004. Transfer of knowledge between education and workplace settings. In Workplace Learning in Context., edited by H. Rainbird, A. Fuller and A. Munro. London: Routledge.

Fuller, A, and L Unwin. 2004. Expansive Learning Environments. Integrating organizational and personal development. In Workplace Learning in Context, edited by H. Rainbird, A. Fuller and A. Munro. London: Routledge.

Furlong, J., L. Barton, S. Miles, C. Whiting, and G. Whitty. 2000. Teacher Education in Transition reforming professionalism? Buckingham: Open University Press.

Garcia-Horta, J.B., and M.T. Guerra-Ramos. 2009. The use of CAQDAS in educational research: some advantages, limitations and potential risks. International Journal of Research and Method in Education 32 (2):151-165.

Greeno, J.G., A.M. Collins, and L.B. Resnick. 1996. Cognition and learning. In Handbook of Educational Psychology, edited by D. Berliner and R. Calfee. New York: Macmillan.

Haggarty, L 1995. New Ideas for Teacher Education. A Mathematics Framework. London: Cassell.

Haggarty, L, and K. Postlethwaite. 2009. An exploration of changes in thinking in the transition from student teacher to newly qualified teacher. Research Papers in Education, First published on: 10 November 2009 (iFirst).

Haggarty, L., and K. Postlethwaite. 2003. Action Research: a strategy for teacher change and school development? Oxford Review of Education 29 (4):423-448.

Hobson, A.J., P. Ashby, A. Malderez, and P.D. Tomlinson. 2009. Mentoring beginning teachers: What we know and what we don't

Teaching and Teacher Education 25 207-216.

Hodkinson, H. , and P Hodkinson. 2005. Improving schoolteachers' workplace learning. Research Papers in Education 20 (2):109-131.

Hodkinson, P., G. Biesta, and D. James. 2004. Towards a Cultural Theory of College-based Learning. In Annual Conference of the British Educational Research Association, . Manchester.

James, D., and G. Biesta, eds. 2007. Improving learning cultures in further education: London, Routledge.

James, D., and J.M. Bloomer. 2001. Cultures and Learning in Further Education. In British Educational Research Association Annual Conference; 3-15 September 2001. University of Leeds.

Kaptelinin, V., and A. Nardi. 2006. Acting with technology: Activity Theory and Interactional Design. Cambridge, Massuchusetts: The MIT Press. 
Lacey, C. 1977. The Socialization of Teachers. London: Methuen.

Lave, J. , and E. Wenger. 1991. Situated Learning: legitimate peripheral participation. Cambridge: Cambridge University Press.

Leontiev, A.N. 1978. Activity, consciousness, and personality Translated by M. J. Hall. Englewood Cliffs, N.J. : Prentice-Hall.

Mahar, C., Harker, R. and Wilkes, C. 1990. The basic theoretical position. In An Introduction to Work of Pierre Bourdieu - The practice of theory, edited by R. Harker, C. Mahar and C. Wilkes. Basingstoke: Macmillan.

Moore, A., and A. Ash. 2010. Reflective practice in beginning teachers: helps, hindrances and the role of the critical other. Paper presented to Annual Conference of the British Educational Research Association at University of Exeter 2002 [cited March 2010]. Available from http://www.leeds.ac.uk/educol/documents/00002531.htm.

Pajares, M. 1992. Teachers' beliefs and educational research: cleaning up a messy construct. Review of Educational Research 62 (3):307-332.

Peressini, D., H. Borko, L. Romagnano, E. Knuth, and C. Willis. 2004. A conceptual framework for learning to teach secondary mathematics: a situative perspective. Educational Studies in Mathematics 56:67-96.

Poulson, L., E. Avramidis, R. Fox, J. Medwell, and D. Wray. 2001. The theoretical beliefs of effective teachers of literacy in primary schools: an exploratory study of orientations to reading and writing. Research Papers in Education 16 (3):271-292.

Richards, C, P Harding, and D Webb. 1997. A key Stage 6 Core Curriculum? A critique of the national Curriculum for Initial Teacher Training. London: Association of Teachers and Lecturers.

Richardson, V. 1997. Constructivist teaching and teacher education: Theory and practice. In CONSTRUCTIVIST TEACHER EDUCATION: BUILDING NEW UNDERSTANDINGS, edited by V. Richardson. Washington DC: Falmer Press.

Schön, D. . 1983. The Reflective Practitioner: How professionals think in action. New York: Basic Books.

Sfard, A., and A. Prusak. 2005. Identity that makes a difference: substantial learning as closing the gap between actual and designated identities In Proceedings of the 29th Conference of the International Group for the Psychology of Mathematics Education, edited by H. L. Chick and J. L. Vincent. Melbourne: PME.

- 2005. Telling Identies: In Search of an Analytic Tool for Investigating Learning as a Culturally Shaped Activity. Educational Researcher 34 (4):14-22.

Shulman, L. S. 1987. Knowledge and Teaching: Foundations of the New Reform. Harvard Educational Review 57 (1):1-22.

Vygotsky, L. 1978. Mind in Society: the development of higher psychological processes. Cambridge, Mass.: Harvard University Press.

Whiteside, M.T., G. Bernbaum, and G. Noble. 1969. Aspirations, reality shock, and entry into teaching. Sociological Review 17 (3):399-414.

Zeichner, K. 1980. Myth and realities: field based experiences in pre-service teacher education. Journal of Teacher Education 31 (6):45-55. 
Zeichner, K.M., and D.P. Liston. 1987. Teaching student teachers how to reflect. Harvard Educational Review 57 (1):23-48.

—. 1996. Reflective Teaching: an introduction. Mahwah NJ USA: Lawrence Erlbaum Associates. 
Biographical details

Keith Postlethwaite is Associate Professor and Deputy Head of School at the School of Education and Lifelong Learning, University of Exeter. He contributes to initial teacher education programmes for science teachers, to research methodology teaching and to doctoral supervision. His research interests are mainly in the field of professional learning, where he has researched ITE, the continued professional development of experienced teachers, and medical education

Linda Haggarty is Postgraduate Tutor at The Open University with responsibility for the professional doctorate in the Centre for Research in Education and Educational Technology as well as being a research degree supervisor. She has also been involved in the development of initial teacher education programmes. Her research interests are in the field of professional learning, with a particular interest in learning to teach mathematics, and the continued professional development of experienced teachers. 
